\title{
Mauricio Macri: historia mediatizada de un presidente argentino
}

\section{Mauricio Macri: publicized historical background of an Argentinian president}

https://doi.org/10.18566/comunica.n44.a03

Recibido: 31 de enero de 2021

Aceptado: 25 de marzo de 2021

\section{Resumen}

El estudio de las imágenes proselitistas de la fuerza política Propuesta Republicana (PRO), liderada por el expresidente Mauricio Macri (2015-2019), constituye una oportunidad para examinar los procedimientos técnicos y semióticos de comunicación utilizados para instalar y posicionar sus candidaturas a jefe de gobierno de la Ciudad Autónoma de Buenos Aires y luego a la Presidencia de la República Argentina. Con el objeto de reconocer regularidades y rupturas en su gramática de producción, en la investigación se analizan imágenes fijas e imágenes en movimiento divulgadas en medios tradicionales de prensa entre los años 2007 y 2019. La metodología ha consistido en la confección de un corpus de imágenes de uso electoral, las cuales han sido examinadas de manera intertextual. Los resultados indican que sus campañas se sustanciaron en la exposición de proximidad entre candidato y electores. Se concluye que este es, en la actualidad, el modelo vigente de comunicación electoral en Argentina.

\section{Abstract}

The study of the canvassing images belonging to the Republican Proposal political party (PRO), led by the ex-president Mauricio Macri (2015-2019), is an opportunity to examine the technical and semiotic communication methods employed for establishing and positioning his candidacies for head of government of the Autonomous City of Buenos Aires and, then, for president of the Argentine Republic. With the purpose of identifying regularities and disruptions in their production structure, this research examines still and in
Comunicación

número 44

Enero-junio

2021 | pp. 36-56

\section{Mariano Cicowiez}

Magister en Estética y Teoría de las Artes, y doctorando en Artes, ambos posgrados cursados en la Facultad de Artes de la Universidad Nacional de La Plata (UNLP). Becario doctoral del Consejo Nacional de Investigaciones Científicas y Técnicas

(Conicet) con sede en el Instituto de Historia del Arte Argentino y Americano, Facultad de Artes de la UNLP. Participa en el proyecto de investigación "El panelismo en la televisión contemporánea argentina. Análisis de los programas y su recepción", con sede en el Instituto de Investigaciones Gino Germani, Facultad de Ciencias Sociales de la Universidad de Buenos Aires. https:// orcid. org/0000-0002-1251-0927 marianocicowiez@yahoo. com.ar

Palabras clave Campaña electoral, comunicación política, imágenes.

Keywords Electoral campaign, political communication, images. 
motion images circulated by the traditional media between 2007 and 2019. The methodology comprised the building of a corpus of images for electoral use, which have been examined on an intertextual basis. The results show that itscampaigns were conducted in accordance with the exhibition of proximity between candidates and electors. It is therefore concluded that, at present, this is the current electoral communication model in Argentina.

\section{Introducción}

El examen de la historia de la mediatización del partido político argentino PRO, conducido por el expresidente Mauricio Macri, permite asegurar que aquella ha implementado un modelo de comunicación audiovisual incluso replicado en el mapa electoral y de gestión ejecutivos por sus principales oponentes. Si efectivamente la elección nacional que alzó a Macri a la máxima jefatura, acontecida en el año 2015, significó el reconocimiento de una estrategia enunciativa novedosa en el campo de las campañas presidenciales argentinas, fijando una ruptura con las acciones proselitistas que en este ámbito la precedieron, no es menos cierto que su origen se remonta aun al inicio de la carrera política del expresidente, acontecido en la Ciudad Autónoma de Buenos Aires hacia comienzos del nuevo siglo. De manera que el estilo de comunicación instituido por el PRO, recusado por los elencos del arco político nacional, ha sido adoptado por ellos en las elecciones legislativas de 2017 y, en mayor medida, en la jornada de renovación presidencial, celebrada dos años después. Desde entonces, la configuración de los mensajes visuales y audiovisuales partidarios argentinos pareciera conducir hacia el triunfo definitivo de una estructura de significación vinculada a la exposición de un grado de equivalencias entre las sociedades de representantes y representados (en menoscabo de proclamas de gobierno), cuyo término o cese de su expansión resulta prematuro definir.

En este sentido, el estudio semiótico de las imágenes técnicas puede contribuir a una comprensión integral de los dispositivos de comunicación que circulan en un proceso eleccionario. El examen de las fotografías y de la banda visual de los spots de campaña se ha vuelto impostergable desde la irrupción en la política electoral de Macri, más aún cuando sus asesores principales han afirmado que...

... La comunicación política de calidad, hecha por televisión, se evalúa sin audio, para saber cuán fuerte es el impacto de sus imágenes en el ánimo de los televidentes. Los comerciales de televisión que presentan al candidato 
hablando en primer plano, con frases complicadas, hilvanando argumentos jurídicos, tratando temas de la vieja política, generalmente no sirven para nada (...). En televisión, las palabras sirven sólo de apoyo secundario para lo que comunican las imágenes. No importa tanto la corrección teórica de lo que dice el candidato, como lo que denota con su rostro y su lenguaje corporal (Durán Barba y Nieto, 2017a, pp. 367-368).

Si bien la personalización de la política argentina ha tenido antecedentes desde al menos la década de 1990, lo cierto es que a partir de la incursión en ella de Macri ha cobrado una nueva densidad, en este caso asociada a la utilización de las imágenes técnicas de alcance masivo. Es en este contexto que proponemos analizar la banda visual de spots y de fotografías en relación con la figura de Macri en calidad del actante excluyente del mundo narrado en las imágenes.

Por lo expuesto, el trabajo que presentamos se orienta menos hacia la discursividad oral que prevaleció en una serie de campañas de elección argentinas que sobre las construcciones simbólicas que, de alguna manera, conformaron los marcos indiciales en los cuales aquella ha sido enunciada. En efecto, el objetivo de nuestro estudio consiste en el reconocimiento de las estructuras visuales/audiovisuales concernientes a imágenes fijas e imágenes en movimiento difundidas, en medios tradicionales de prensa, por la fuerza política PRO, con el objetivo de examinar la composición en la diégesis de los cuerpos, los objetos y los espacios que la integran.

Nuestra hipótesis hermenéutica, habíamos adelantado, sugiere que el modelo de comunicación visual/audiovisual implementado, en el ámbito nacional, por el PRO en las elecciones presidenciales del año 2015 ha replicado la estructura de los anuncios que dicha fuerza instituyó desde sus inicios políticos, localizados en la Ciudad Autónoma de Buenos Aires, y que dicho modelo luego ha sido aplicado por las fuerzas partidarias de signo contrario.

El entramado conceptual incluye autores vinculados a los campos (i) de la comunicación política, cuyos estudios remiten tanto al presente contexto de difusión de mensajes partidarios en medios tradicionales de prensa como al inicio formalmente establecido de la mediatización de las campañas electorales argentinas, acontecido en el año 1983,y (ii) de la semiótica audiovisual, respectiva a las estrategias discursivas en las cuales se insertan las imágenes en el proceso de su circulación, como, asimismo, al grado de implicación que operan las diversas materias significantes que las conforman. 


\section{Estado de la cuestión}

El estado del arte comprende la línea de investigación que, en Argentina, Rocío Annunziata $(2013,2014,2018)$ desarrolla acerca de la proximidad (Rosanvallon, 2009) que en la actualidad se establece entre representantes y representados a través de diversas estrategias de comunicación política, tal y como acontece en la denominada acción de timbreo en los domicilios particulares de la sociedad civil. En esta misma dirección, nuestra investigación privilegia el estudio de los recursos de composición pertenecientes a la enunciación fílmica, con el objeto de reconocer los procedimientos tecnológicos naturales a las imágenes fijas y a las imágenes en movimiento, privilegiados en el armado de las estrategias electorales argentinas.

En efecto, continuamos con el examen de la personalización de la política (Castells, 2009), la cual ha sido denominada, en relación con el caso específico de Macri, con el añadido "híper" (Riorda, 2016) debido a la maximización de este procedimiento, observado en nuestro estudio sobre la banda visual de las imágenes. Recordemos que Boris Groys (2014) señala que en el ámbito de la política contemporánea comportan poca relevancia los contenidos de los programas de gobierno, debido a que "bajo el régimen del diseño moderno, el posicionamiento visual de un político en el campo de los medios masivos es justamente el que hace una afirmación crucial sobre su acción política" (2014, p. 34). Este posicionamiento es el que han predicado los asesores de comunicación Jaime Durán Barba y Santiago Nieto (2017a, 2017b) en las campañas electorales protagonizadas por Macri.

\section{Metodología}

El marco metodológico consistió, como primera medida, en la composición de un corpus de imágenes fijas y móviles difundidas durante el período que abarca nuestro estudio. A través de un reconocimiento intertextual de producciones concernientes a cada una de las tres elecciones de candidaturas (2007, 2015 y 2019) han sido seleccionadas aquellas unidades que operan en cuanto síntesis del universo al cual pertenecen. Es decir, que las imágenes que conforman las muestras focales de observación presentan una serie de recursos de composición regulares con respecto al corpus en el cual se incluyen.

Hemos desagregado el estudio en tres niveles de significación: el nivel supraunitario, conformado por una campaña de elección argentina; el nivel unitario, establecido por imágenes fotográficas y televisivas; y el nivel subunitario, en razón de tres materias de significación: la primera integrada por los cuerpos de Macri y los figurantes (Bourriaud, 2008) civiles incluidos 
en las representaciones; la segunda referente al conjunto de objetos (Barthes, 1986) que connotan a la integridad de la información dispuesta en el cuadro; y la tercera acerca de la topografía espacial en la cual acontecen los esquemas narrativos diseñados por el PRO.

Al respecto, cabe primero la siguiente distinción: las producciones técnicas de 2007 han sido registradas bajo la modalidad denominada en directo y aquellas pertenecientes a los dos siguientes procesos eleccionarios en un régimen grabado. De modo que si las segundas han sido elaboradas por los equipos de campaña partidarios, las primeras constituyen un fotograma y una fotografía pertenecientes a medios de comunicación. Esta distinción no es menor, debido a que implica que de la campaña 2007 hemos recuperado imágenes cuyo interés analítico se ubica en las materias de significación que componen su estructura, por sobre el sujeto enunciador que las conforma. Esto es, capturas similares han sido tomadas por distintos agentes de prensa, siendo ellos indistintos a los objetivos de nuestra investigación.

Por tal motivo, imágenes afines a las nuestras han circulado en 2007 con leves variaciones de su angulación, iluminación, entre otros aspectos, de acuerdo con la ubicación espacial de los dispositivos tecnológicos. Debido a que estas variaciones no modificaron la estructura general de los eventos que registran, la elección de las Imágenes $\mathbf{1}$ y $\mathbf{2}$ ha sido realizada mediante un procedimiento de azar.

Las Imágenes 3, 4 y 5 han sido extraídas de anuncios audiovisuales elaborados por las alianzas Cambiemos (en 2015) y por Juntos por el Cambio (en 2019), en las cuales participó el PRO. Su mundo narrado ha sido reconocido en diversos avisos televisivos e incluso reiteradamente en un mismo spot, por lo cual hemos tenido en cuenta, al momento de su elección, las siguientes dimensiones: relación de proximidad entre el candidato y los electores; espacio referencial compuesto por sitios de trabajo o de vivienda; registro de obras públicas elaborado por los ciudadanos. El volumen de spots pertenecientes a 2015 supera las 80 producciones, mientras que este número se reduce a una cuarta parte en la siguiente elección presidencial.

En su conjunto, las unidades focales representan imágenes de síntesis acerca de procedimientos de composición visual y audiovisual, por lo que el estudio de muestras particulares dará cuenta del universo al que pertenecen. Resta mencionar que los actos proselitistas registrados en las Imágenes $\mathbf{1}$ y $\mathbf{2}$ constituyen hechos icónicos del proceso eleccionario 2007 ( por caso, ambos suscitaron innumerables debates en los medios de prensa de época), por lo cual con ellas iniciamos nuestro recorrido analítico. 
Finalmente, para concluir esta presentación, destacamos que el impacto que pretendemos alcanzar a través de esta investigación consiste en la producción de un texto que abarque desde los históricos inicios de la propaganda del PRO hasta el tiempo presente, con el fin de reconocer la génesis del estilo de comunicación política que privilegia la vigente estructura de los principales partidos políticos argentinos.

\section{Comienzos de la mediatización política en Argentina}

El bautismo de la mediatización de las campañas argentinas tuvo un antecedente en el año 1973, cuando el partido Nueva Fuerza, fundado el año anterior por Álvaro Alsogaray, incorporó una serie de medidas por entonces novedosas en el campo de la comunicación política nacional. En aquellas elecciones, que culminaron con el triunfo del Frente Justicialista de Liberación (Frejuli), cuya nómina presidencial fue integrada por Juan Domingo Perón y Vicente Solano Lima, Nueva Fuerza difundió spots televisivos de carácter proselitista.

No obstante la exigua cantidad de votos obtenidos por Nueva Fuerza, cuyo porcentaje se ubicó en el 2, sus acciones de campaña antecedieron a las medidas adoptadas en la siguiente elección, acontecida en 1983 (Borrini, 2003), la cual selló la inclusión definitiva de los medios tradicionales de prensa a la estrategia de difusión de candidaturas. Tras el período que representó la toma inconstitucional del poder por la Junta Militar durante el período 1976-1983, la apertura democrática significó, en el plano partidario, una oportunidad para que las fuerzas políticas diesen a conocer sus propuestas y programas de gestión por intermedio de las características masivas de recepción del dispositivo televisivo.

De acuerdo con la tesis de investigación perteneciente al politólogo Óscar Landi (1992a), la instalación definitiva de la televisión en Argentina como plataforma de difusión de mensajes partidarios se debió a que, durante el gobierno de la Unión Cívica Radical (UCR) de Raúl Alfonsín (1983-1989) se produjo una ruptura en el orden de la credibilidad de la enunciación discursiva de la palabra presidencial, por lo cual la clase dirigente comenzaría, desde entonces, a frecuentar nuevos espacios y propuestas televisivas más próximas a los envíos de interés general e, incluso, de entretenimientos, para recrear un nuevo régimen de contacto con la ciudadanía. ${ }^{2}$ En este sentido, Landi (1992b) destaca en una ponencia titulada "Política y comunicación. ¿Hay un lugar para la política en la cultura mediática?" la prevalencia del dispositivo televisivo como medio de comunicación político:
1 Álvaro Alsogaray, quien fuera ministro del Interior durante la presidencia de Arturo Frondizi (1958-1962), representa el ala más conservadora de la política argentina. Fue el fundador de la Unión del Centro Democrático (UCeDé). Las elecciones de 1973 significaron el retorno a la presidencia de la Argentina de Perón, luego de permanecer 18 años en la ciudad de Madrid.

2 Durante el denominado levantamiento carapintada de la Semana Santa del año 1987, una fracción del Ejército se rebeló contra sus mandos superiores en la Escuela de Infantería de Campo de Mayo, situado en Buenos Aires. Esta situación produjo una manifestación ciudadana frente a la Casa de Gobierno, en la histórica Plaza de Mayo, la cual culminó con un discurso de Alfonsín en el cual señaló, luego de su intervención en el conflicto, el cese de las acciones militares, aunque acaso sin el rigor que imponía dicho alzamiento. Este hecho, asegura Landi (1992a), marcó la ruptura definitiva de la credibilidad de la palabra presidencial y de un tipo de discurso político basado en la teatralización del lenguaje corporal. 

la expansión de la TV como escenario principal y también como actor de la política (1992b, pp.36,37).

De este modo, el discurso verbal de los candidatos pronunciado desde la oficialidad de un atril montado sobre un escenario comenzaba, en los primeros años de la década del 80, a confirmarse como un soporte de sentido quizás necesario, pero no suficiente para establecer una instancia de comunicación entre dirigentes acuciados por la crisis de representación argentina y una sociedad que, como asegura Silvio Waisbord (1995), empezaba a mostrar signos de incertidumbre hacia el nuevo período democrático inaugurado con la asunción de Alfonsín:

El desencanto con la democracia sumado a la fragmentación de identidades políticas (la ruptura del llamado "electorado de pertenencia") que caracterizara el mapa electoral argentino por décadas afectó profundamente el armado de las campañas electorales. A diferencia de tiempos pasados, causas célebres como nacionalismo, antiimperialismo, igualdad social o democracia no movilizan grandes masas de votantes (1995, p.56).

Esta breve exposición acerca de los inicios de la mediatización de las campañas electorales argentinas constituye los antecedentes sobre los cuales el PRO conformó la gramática de diseño de sus avisos electorales televisivos. En los siguientes apartados examinaremos las unidades de observación manteniendo el orden cronológico de su difusión en soportes visuales y audiovisuales.

\section{Resultados y discusión}

\section{La campaña 2007}

La primera imagen se corresponde con el acto de lanzamiento oficial de la campaña del PRO a la jefatura de gobierno de la Ciudad Autónoma de Buenos Aires (Imagen 1). En un barrio marginal de la localidad de Villa Lugano, el 26 de febrero de 2007 Macri presentó su candidatura durante un evento que sería recordado más por la estética que ilustró la puesta en escena desde la cual enunció su discurso que por el contenido de sus programas de gestión. Ubicado sobre una improvisada tarima de maderas, el conductor de la fuerza política fue acompañado por una niña cuya presencia generó las mayores controversias debido a que su inclusión en las imágenes fijas y móviles que registraron el acontecimiento partidario habilitó el debate acerca de 
la utilización mediática de jóvenes en situación de pobreza. Detrás de los cuerpos de los protagonistas se ven residuos arrojados sobre el suelo, en un vertedero de basura al descubierto. La posición axial de Macri realza la visibilidad de una situación social con frecuencia ausente de las campañas electorales argentinas. En este sentido, la ubicación próxima del candidato junto a la niña, los desperdicios materiales y el espacio referencial constituyen los indicadores que reenvían a nuestro objeto de estudio.

\section{Imagen 1. Acto de lanzamiento oficial de la campaña del PRO.}

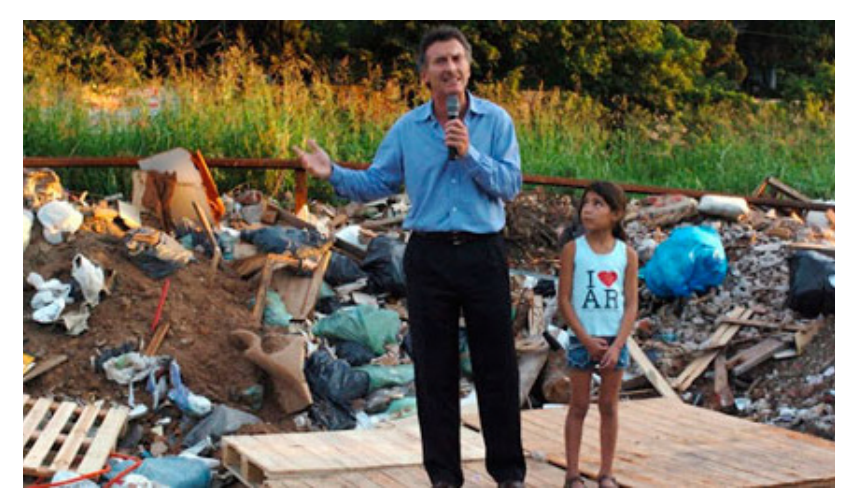

Fuente: Morielli (2011).

Si efectivamente hablamos de puesta en escena, es debido a que la información significante que constituyen el basural y la vestimenta de la niña que luce lo que su voz no afirma (porque el uso de la palabra corresponde al líder del PRO) se trata, sin dudas, de elementos diseñados en la gramática de producción de las imágenes que los medios tradicionales de comunicación habrían de difundir. Es en este sentido que resulta pertinente examinar la naturaleza indicial de los dispositivos técnicos de comunicación.

En los dos tomos que conforman Estética y psicología del cine, publicados por Jean Mitry en 1963, se advierte un acumulado de indicaciones que reenvían a la segunda tricotomía del signo elaborada por Charles S. Peirce (1974), fundador de la semiótica moderna: Mitry $(1998 ; 2006)$ concluye que la realidad no es aprehensible más que a partir de una de sus circunstancias. En el estudio, asevera que la realidad sobre la cual la película cinematográfica no organizaría ninguna selección y trabajo de puesta en escena en verdad siempre se encuentra sujeta a un proceso de mediatización que la reconstituye en un carácter similar, y por tanto no en condiciones equivalentes. Entre la representación de la realidad y aquello que efectivamente representa, se interponen intervenciones que imposibilitan su estatuto duplicado: “... lo real cinematográfico es un real mediatizado. Entre el mundo real y nosotros 
está la película, la cámara, la representación, en el caso límite de que no haya, por añadidura, un autor" (la letra itálica pertenece al texto original) (Mitry, 1998, p.7).

Los estudios de Mitry resultan pertinentes para examinar la reconversión del espacio referencial en escenario de uso proselitista, efectuada a través de las fotografías de prensa y las horas de video difundidas en los noticieros televisivos. La Ciudad Autónoma de Buenos Aires, y asimismo vastos conglomerados urbanos ubicados en la provincia de Buenos Aires, se corresponde con las áreas geográficas en las que predominan los mayores indices de pobreza argentinos. En este sentido, y debido a la naturaleza del dispositivo tecnológico de filmación, no es posible sino registrar un aspecto de una realidad que excede, en este caso, a la estructura de significación que muestra la imagen fija, la cual, en efecto y sin embargo, da cuenta de la presencia de Macri en un basural.

Desde hace décadas, la Argentina padece una línea de pobreza estructural imposible de trasladar al ámbito de los lenguajes fílmicos y fotográficos, por lo que el PRO no hizo más que seleccionar, durante el acto de lanzamiento partidario, un área geográfica, a modo de figura de composición de sinécdoque, para presentar "la parte por el todo" que alcanzase a reflejar el orden de una situación económicamente desfavorable. En este sentido, la imagen actúa en razón de la lógica de la mímesis (Dubois, 1986), debido a que su cometido ha sido divulgar un cuadro de composición "semejante" al hecho que traslada al espacio de representación que constituye la materialidad de la fotografía.

Recordemos que, por entonces, Macri era mal percibido por un amplio sector de la sociedad, tal y como recuerda Hernán Iglesias Illa (2016), asesor de su campaña electoral y autor de un texto que repasa el armado y ejecución de cada una de sus etapas: "Mauricio era un candidato percibido por la sociedad como inteligente y preparado, con el potencial para ser un gran presidente, pero no del todo confiable todavía" (2016, p.17). La falta de credibilidad se debía a su injerencia en las empresas de su padre, Franco Macri, dueño de uno de los mayores grupos económicos de la Argentina. Con el objeto de revertir dicha apreciación, en 1995 incursionó con éxito como dirigente del club deportivo Boca Juniors, lo cual facilitó el paso, cinco años después, hacia el campo de la política electoral.

Algunos días después de presentar su candidatura, Macri replicó una acción proselitista que había incursionado en 2005, durante la campaña a diputado nacional por la Ciudad Autónoma de Buenos Aires, en la cual resultó elegido (Imagen 2). La puesta en escena de la imagen replica la estructura de la unidad de observación precedente. Vemos un espacio público en mal 
estado de preservación y un dirigente que allí se presenta para dar cuenta del incumplimiento de los deberes del Estado. La franja de pastos crecidos donde debiera disponerse el asfalto indica una señal de abandono. De esta manera, Macri traslada su campaña electoral hacia sitios seculares donde transita la ciudadanía.

La ciudad presentaba, por entonces, una importante cantidad de depresiones en sus arterias asfálticas que dificultaba el tránsito de autos y causaba malestar entre sus conductores. Por tal motivo el candidato, en sus recorridos frecuentes por los distintos barrios urbanos, llevaba a cabo una medida conocida como "el salto del bache", la cual era fotografiada y difundida en medios tradicionales de comunicación.

\section{Imagen 2. Macri haciendo "el salto del bache".}

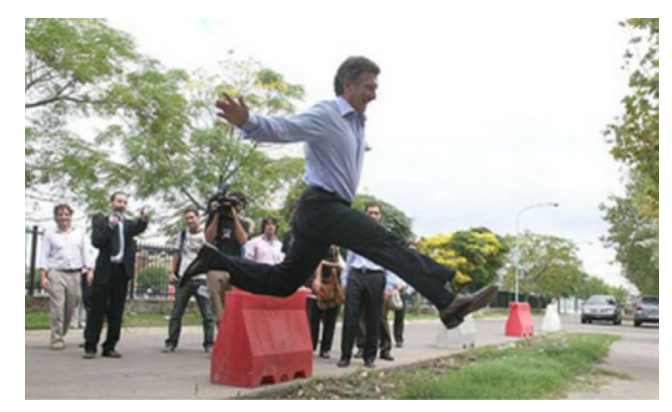

Fuente: Infobae (2007).

La imagen captura el instante esencial (Schaeffer, 1990) en el que Macri realiza una acción acaso infrecuente según la conducta que solicita la investidura de su cargo como diputado nacional para obtener la jefatura de la Ciudad Autónoma de Buenos Aires. La medida resultó novedosa en el campo de las acciones de propaganda política mediatizada argentina debido a la ruptura del orden de la gestualidad de los cuerpos acostumbrada de los dirigentes partidarios. La representación audiovisual consuetudinaria de los candidatos concerniente a períodos electorales distaba de aquella que los equipos de comunicación de Macri diseñaron en los años 2005 y 2007. De este modo, las imágenes técnicas del PRO establecieron un nuevo régimen de contacto con los electores, en razón de la exposición de un cuerpo político que irrumpía las expectativas más arraigadas acerca de sus códigos kinésicos, proxémicos y dramáticos (Gubern, 1987).

En efecto, "por la mediatización, un lazo secreto se teje entre el cuerpo significante (...) y esa concretización de la ley que es, en democracia, el cuerpo del presidente" (Verón, 2001, p.39). Si el mando presidencial, en 
particular, y la suma de cargos públicos, en general, se construyen en relación con un sistema legal al cual se remite a través de la exposición de sus cuerpos, estos se hallan sujetos a prohibiciones que limitan su desenvolvimiento. Debido a que los signos se definen por negación, de acuerdo con las diferencias que se establecen en estado de relación, la imagen del cuerpo de Macri ha definido su estatuto, en la unidad que sirve de muestra a nuestra investigación, a través, por ejemplo, de acciones ajenas a su ámbito de desarrollo natural.

El contrato que vincula las expectativas del consumidor de un servicio audiovisual en relación con la imagen de un candidato, por ejemplo, a la jefatura de la Ciudad Autónoma de Buenos Aires, incluye no solo el campo de los contenidos de los enunciados verbales, sino que concursa, además, la serie de movimientos que el candidato efectúe con su cuerpo. Eliseo Verón (1999) recuerda que en una campaña de elección presidencial acontecida en Francia hacia inicios de la década del 80, uno de los candidatos quebró el mandato que vinculaba su investidura y la recepción mediatizada a través de la televisación de sus actos partidarios:

Coluche había puesto en escena el anticuerpo presidencial. Le había recordado a la sociedad que todo cuerpo socializado, y el cuerpo presidencial más que ningún otro, está construido con prohibiciones, está tallado a través de anulación de actos, neutralización de ciertas trayectorias, censura de gestos y de posturas (1999, p. 87).

Es en este sentido que "el salto del bache" constituyó una acción de campaña pertinente para reconfigurar la imagen del candidato del PRO. Si efectivamente Macri era percibido como garante de la continuidad de los aspectos más perniciosos de la política argentina, entonces los dispositivos fijos y móviles de comunicación oficialmente difundidos por su fuerza partidaria debían representar una escena visual subsidiaria de la renovación de las prácticas de gobierno ejecutadas por una nueva clase dirigente. La presencia de Macri en la vía pública, es decir, en un espacio de tránsito compartido con la ciudadanía, significó la exhibición de un aspirante cercano a las necesidades irresueltas de los habitantes de la ciudad, en un contexto de crisis de representación partidaria que en Argentina tuvo su punto más crítico durante el período 2001-2002. ${ }^{3}$

Los elementos que connotan a la fotografía (Barthes, 1986) se corresponden con la serie de señaladores rojos y blancos que indican, a los conductores de vehículos, el mal estado de las arterias asfálticas. Frente a las habituales presencias de candidatos en escenarios especialmente montados para sus actos de propaganda, ubicados sobre un atril y dirigiéndose a la concurrencia a través de la ampliación de su voz por intermedio de un
3 En diciembre de 2001, el presidente Fernando de la Rúa renunció a su cargo debido a una serie de factores políticos, sociales y económicos que anticiparon, por caso, el anuncio del cese del pago de la deuda externa, denominado default. Por aquellos días, la sociedad bregaba una consigna que traducía el hartazgo con respecto a su clase dirigente: "Que se vayan todos". 
artefacto tecnológico (y luego reproducidos en espacios de televisión de aire y prepaga), el PRO divulgó imágenes cuya estructura de significación contrastaba con el modelo de comunicación que escinde a las sociedades política y civil (Durán Barba y Nieto, 2017b). La reducción de las distancias entre representantes y representados se visualiza en el espacio compartido en el cual acontece el programa argumental de la fotografía, la acción cuasideportiva que Macri ejecuta y la vestimenta que luce en tal evento.

La irrupción del candidato en un espacio público para practicar una medida electoral novedosa supuso, además, la exhibición de un aspirante que expresaba la renovación de la dirigencia incluso desde la informalidad de las prendas que vestía. Durante su campaña, tal y como muestra la imagen, Macri desconoció las reglas de etiqueta/conformidad que señalan la utilización de saco y corbata, estableciendo así un régimen corporal del contacto sustanciado en la proximidad de los gobernantes con respecto a los usos y prácticas ciudadanos. Sobre la significación del traje hacia el interior de una estructura fotográfica, John Berger (1998) señaló que "se desarrolló en Europa durante el último tercio del siglo XIX como un vestido profesional de la clase dirigente (...). Esencialmente, el traje fue hecho para la gestualidad que acompaña a la charla y el pensamiento abstracto" (1998, p.51).

En tal sentido, Macri rechazó una vestimenta que lo desvincularía de la imagen de un dirigente con capacidad de resolución de las demandas más inmediatas de la ciudadanía y, por tanto, distanciado de los tradicionales partidos políticos argentinos fundados sobre el final del siglo XIX y mediados del siglo XX. Esta medida forma sistema con la exposición del candidato en un basural de residuos contaminantes.

\section{La campaña 2015}

La campaña nacional celebrada en 2015 estableció una oportunidad para que el partido liderado por Macri, asentado mayoritariamente en la Ciudad Autónoma de Buenos Aires, desplegase un radio de operación nacional, para de este modo constituirse en una opción electoral en las 24 provincias que conforman a la Argentina. Para ello, el PRO hizo una alianza con la tradicional fuerza Unión Cívica Radical (UCR) y con Acción para una República de Iguales (ARI) (integrante de una coalición llamada, justamente, Coalición Cívica), que, por entonces, concitaba una atención considerable en un sector de la ciudadanía. El producto de la unificación de fuerzas fue la conformación de la coalición Cambiemos, bajo la cual los principales referentes de los tres partidos dirimirían la candidatura presidencial en una interna abierta.

Recordemos que el sistema electoral argentino tiene las siguientes instancias de votación: (i) la primera comprende la jornada denominada "primarias 

municipales, provinciales y nacionales. Aquellos precandidatos que resultan elegidos representan a sus respectivos espacios partidarios; (ii) la segunda corresponde a la primera vuelta electoral: un candidato a la Presidencia gana cuando el porcentual de votos obtenidos supera el 45 o cuando no alcanza dicho porcentual, pero una diferencia mayor a $10 \%$ lo separa del contendiente más cercano; (iii) la tercera se denomina balotaje: cuando no cumplen los requisitos mencionados, los dos candidatos más votados definen el triunfo electoral en una segunda y definitiva vuelta. El balotaje solo corresponde a la candidatura nacional, por tanto no incluye a los cargos municipales y provinciales.

Por tal motivo, Cambiemos presentó para competir en las PASO tres precandidaturas a presidente y vicepresidente de la nación: una por el PRO, integrada por Mauricio Macri y Gabriela Michetti; otra por la UCR, conformada por Ernesto Sáenz y Lucas Llach; y la tercera por Coalición Cívica, encabezada por Elisa Carrió y Héctor Flores. La fórmula que alcanzase el mayor porcentual de votos representaría al espacio político para competir en la primera vuelta electoral (como anticipamos, resultó vencedora la nómina presidida por Macri).

Nuestra tercera muestra de observación es un spot televisivo titulado En cada rincón estamos juntos (Mauricio Macri, 2015a, 00:48), el cual fue difundido en las PASO con objeto de posicionar, en el ámbito nacional, a Macri bajo caracteres contrarios al apercibimiento que de su figura aún conservaban sectores vastos del electorado argentino. El esquema general del anuncio consiste en la exhibición de encuentros que el por entonces precandidato sostuvo en diversas regiones argentinas en las casas o sitios de trabajo de ciudadanos que lo recibieron con agrado y muestras de retribución.

Por tal motivo, la imagen exhibe un cuerpo solícito a acompañar el desempeño cotidiano de los trabajadores del transporte urbano, un espacio de encuentro vinculado al uso común de la ciudadanía y un objeto que, dispuesto en posición axial, connota al conjunto de la representación. En efecto, el equipo de mate desempeña, en la estructura de la imagen, el núcleo sobre el cual reposa el programa argumental de esta (Imagen 3). El espacio referencial es el pasillo interior de un colectivo de transporte de pasajeros de corta y media distancia, en el cual Macri mantiene una conversación distendida con dos de sus trabajadores. El transporte público es utilizado, en mayor medida, por las clases económicas medias y bajas argentinas, por lo cual la presencia allí del dirigente ilustra su acercamiento con la ciudadanía. 


\section{Imagen 3. En cada rincón estamos juntos.}

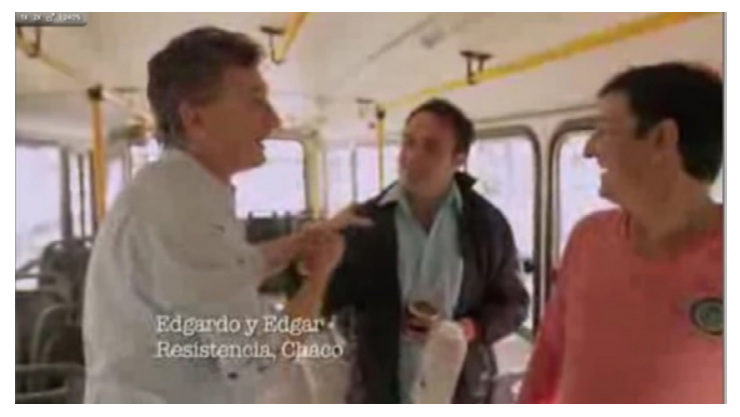

Fuente: Mauricio Macri (2015a).

El encuentro entre Macri y los trabajadores acontece, como primera medida, ocultando la intervención del artefacto tecnológico. Ambos actantes, uno político y otro civil, simulan no advertir la presencia de la lente de filmación, con lo cual el sujeto impersonal de la enunciación construye el texto audiovisual ocultando la puesta en escena que, en verdad, se reconoce en la unidad de observación. Al respecto, Christian Metz (1979) recupera la distinción de Émile Benveniste acerca de una historia que se relata a sí misma, en oposición al orden de un discurso que reconoce su origen en la fuente que lo enunció.

En efecto, Metz no duda en afirmar que el cine se trata de un texto elaborado en calidad de discurso, en el cual el sujeto enunciador vierte las huellas de sus operaciones, que lo constituyen como materia significante. Por tanto, la historia no existe en cuanto tal, sino un discurso elaborado, en el caso que aquí desarrollamos, en la instancia de producción de los avisos partidarios. De modo que el encuentro entre Macri, Edgardo y Edgar ha sido reglado en la gramática de producción del PRO para mostrar al precandidato como a un dirigente inmediatamente atento a la resolución de los conflictos que atraviesa la clase trabajadora argentina. Para ello fue preciso exponer una serie de representaciones audiovisuales que ocultasen la puesta en escena de los elementos y espacios de su estructura.

Alain Touraine (1998) asegura sobre los cometidos que persigue la comunicación política: “... es menester que aparezca como salvador del país, como el defensor de las libertades y protector de los débiles, y no sólo como quien, de un modo puramente instrumental, combina estos tres órdenes de exigencia" (1998, p. 53). Esta medida ha sido replicada por el PRO y trasladada desde el ámbito de la discursividad verbal hacia el campo de las imágenes de uso electoral. 
La siguiente unidad de observación comprende un fotograma extraído de un spot que acaso, desde su difusión en la jornada de las PASO, haya adquirido su carácter icónico por el texto verbal que atraviesa la banda de sonido de la propaganda titulada Pobreza cero en la Argentina (Mauricio Macri, 2015b, 00:47).

El anuncio consiste en la exhibición de dos cadenas de imágenes montadas paralelamente. En una serie, Macripronuncia un discurso ubicado sobre un escenario denominado $360_{-}^{\circ}$, y a aquella le intercalaron imágenes que, en su conjunto, muestran encuentros que el precandidato sostuvo con ciudadanos en los vanos de acceso a sus domicilios, o bien escenas que representan visualmente los conceptos principales incluidos en el enunciado del líder del PRO. Ambas cadenas de imágenes son atravesadas por el siguiente discurso:

Macri:__es propongo universalizar un ingreso ciudadano. Y les propongo que encaremos un pacto para generar una revolución en la calidad de la educación pública. Y otra revolución con los planes de infraestructura. Tenemos que poner un eje fundamental en la vivienda. Esa es nuestra tarea. Es lograr que este país sea un país donde todos tenemos un proyecto de progreso, donde todos sentimos que mejoramos todos los días. Les propongo pobreza cero en Argentina (Mauricio Macri, 2015b).

La imagen seleccionada resulta subsidiaria del plan de construcción de viviendas propuesto por Macri, debido a la posición de su cuerpo, que permite al espectador observar una pared sin revocar y franjas de muro cuyo cemento está al descubierto. Este estilo de composición, que ubica información significante detrás de los protagonistas de los anuncios, vinculada a obras de construcción irresueltas o estructuras utilizadas para la protección de las viviendas (Imagen 4), ha sido replicado en diversos avisos de propaganda. Debido al ángulo de la cámara, la imagen muestra, tras las mujeres que reciben al dirigente, el pórtico y frente de su vivienda. Vemos que Macri es quien se desplaza hacia el lugar donde acontece el encuentro, desprovisto de agentes de prensa oficiales, y se privilegia el contacto directo entre las ciudadanas y el dirigente.

Entre las demandas mayoritarias de la ciudadanía argentina se hallaban, por entonces, el combate a la inseguridad en zonas urbanas y la pobreza que aquejaba, y aún lo hace, al territorio de la nación. De modo que en las imágenes de uso electoral se debía establecer una puesta en escena que correspondiese a la instalación de Macri en calidad de un candidato que inmediatamente concierta su vocación de representación hacia los intereses más próximos de la ciudadanía. En este sentido, se orientó la ubicación de los elementos (materialidad de edificación), el espacio (calles de tránsito 
corriente para el ciudadano/elector) y cuerpos políticos que, en posición de escucha, atienden los reclamos que guiarán el curso de su gobierno.

\section{Imagen 4. Pobreza cero en la Argentina.}

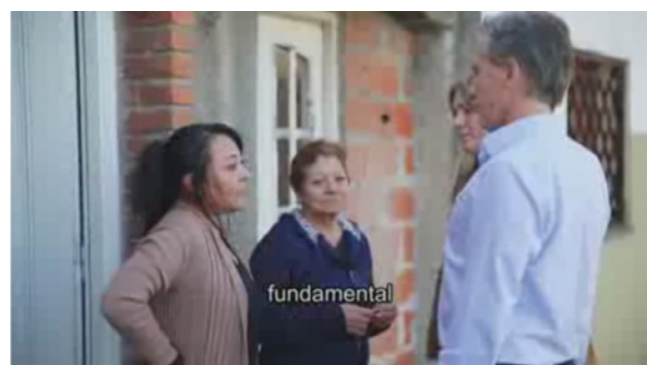

Fuente: Mauricio Macri (2015b).

Dicha corporeidad es la que ha prevalecido en las imágenes electorales diseñadas, a lo largo de su historia, por la fuerza política PRO.

\section{La campaña 2019}

Durante la última campaña de elección presidencial argentina, celebrada en el año 2019, la alianza Cambiemos mudó su denominación a Juntos por el Cambio. Esta nueva coalición incluyó a figuras del peronismo opuestas al sector conducido por la expresidenta Cristina Fernández, quien designó a Alberto Fernández para que encabezase la fórmula nacional de Frente de Todos.

Debido a una serie de factores, principalmente de orden económico, cuyo análisis exhaustivo excede los alcances de este trabajo, Juntos por el Cambio diseñó una estrategia electoral que privilegió la exposición de obras públicas realizadas en los cuatro años de gestión de Cambiemos. El gobierno de Macri fue recusado por no alcanzar a satisfacer las expectativas que en 2015 suscitó su triunfo electoral, por lo que en esta nueva campaña sus equipos de comunicación se abocaron a la exhibición de diferentes rutas y caminos asfaltados, para dar cuenta efectiva de las medidas ejecutadas y culminadas en su período.

La estructura audiovisual de los spots televisivos consistió en la incorporación de ciudadanos que con sus cámaras móviles registraban obras emplazadas en sus propios barrios o en vías de paso interestatal. En todos los casos, las imágenes incluidas en los anuncios de Juntos por el Cambio fueron capturadas por la figura que Metz (1991) denominó "enunciador primero": en este caso, corresponde a los protagonistas que con sus teléfonos 
visibilizaban medidas concretas que contraponían a la percepción negativa del gobierno de Macri las obras arquitectónicas mencionadas (Imagen 5). La imagen muestra una estación de ferrocarril construida durante la gestión de Cambiemos. Se reconoce el óptimo estado de conservación de su arquitectura y, sobre la banda de sonido, la aprobación de la persona que la registra con su teléfono móvil.

\section{Imagen 5. Juntos por el Cambio.}

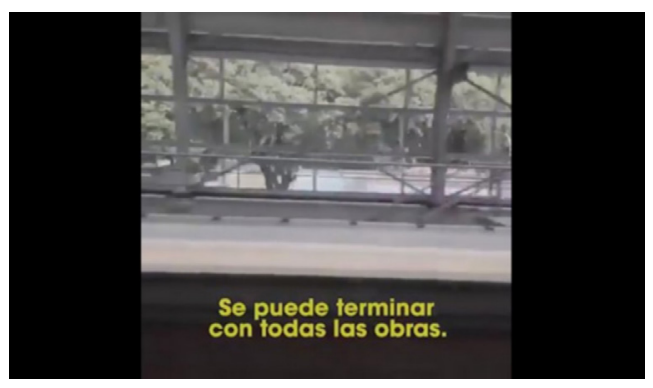

Fuente: Coalición Cívica ARI Malagueño (2019).

La segunda tricotomía del signo peirciano es una clasificación adecuada para examinar el estatuto ontológico de las imágenes recogidas por los figurantes civiles. En relación con el objeto dinámico, los signos se dividen entre aquellos cuya conexión se produce por (i) una asociación de semejanza, (ii) a través de la unión de dos experiencias/contigüidad y (iii) por intermedio de una ley o convención. Las definiciones clásicas de Peirce acerca de los signos icónicos, indiciales y simbólicos han sido objeto de examen en el campo de los estudios de la imagen fija y la imagen en movimiento, por lo que su instrumentación en nuestro estudio resulta pertinente.

El autor propone un método para reconocer el estatuto icónico, indicial o simbólico que predomina en cada signo, ya que ellos conviven por igual hacia el interior de dicho signo. Por lo tanto, (i) el signo icónico puede prescindir del objeto dinámico para adquirir su propia efectividad; (ii) el signo indicial desaparecería si el objeto dinámico del cual emana perdiese su existencia, mientras que (iii) el signo simbólico, para actuar en cuanto tal, requiere de un interpretante que produzca en su mente la conexión que se establece con su objeto dinámico (Peirce, 1974).

De modo que para contrarrestar las críticas a su gobierno, la estrategia de comunicación de Juntos por el Cambio ha consistido, en el campo de la comunicación televisiva, en la exhibición de signos indiciales "afectados" por las obras inauguradas durante sus cuatro años de mandato. La contigüidad 

de los ciudadanos ubicados fuera de cuadro, cuando autentifican, a través de sus exclamaciones, la existencia del objeto dinámico del cual emanan sus filmaciones. En este sentido, cada oración incluida en la siguiente cita remite a un ciudadano que con su teléfono celular ha filmado las imágenes que muestran la finalización de las obras:

Se empezó y se terminó. Se puede terminar con todas las obras. Hoy se termina la obra. Terminada la cuneta. Estamos terminando la obra de energía renovable. Ya terminada. Se termina una obra, está bien hecha. Terminada. Se van terminando. Están terminando el puente de la 34. Recién terminada. Terminando la obra. Terminando las veredas. 30 kilómetros terminados. Verlo terminado. Ya hecho y terminado. Terminada al fin. Ya terminado (Coalición Cívica ARI Malagueño, 2019).

La serie de avisos en los cuales la estructura es establecida por las voces y las imágenes capturadas por los ciudadanos incluye más de 10 producciones audiovisuales, las cuales muestras un aspecto de la realidad de la que emanan.

En definitiva, el conjunto de imágenes de muestra de observación da cuenta de la legitimidad de proximidad, la cual es definida por Rosanvallon (2009) en los términos siguientes:

Remite más bien a un conjunto de expectativas sociales concernientes al comportamiento de los gobernantes (...). A los términos clásicos para comprender el lazo representativo se agregaron así las referencias a la atención, la escucha, la equidad, la compasión, el reconocimiento, el respeto, la presencia (2009, p. 35).

Las dos primeras capturas sustancian su estructura en la presencia de Macri allí donde la ciudadanía observa incumplimientos de los deberes del Estado. El acto partidario llevado a cabo junto a un bolsón de residuos de basura y el salto de un bache ubicado en una arteria de tránsito vehicular exponen el reconocimiento que el candidato efectúa acerca de su irresolución. De igual manera, las Imágenes 3 y 4 estructuran su diseño visual en razón de la presencia, pero más aún en la atención y la escucha que el dirigente profesa hacia la sociedad civil en sus respectivos sitios de vivienda o de trabajo. La última muestra expone el cumplimiento del mandato de realización de obras públicas, cuya exhibición indica un desempeño que alcanza a cubrir las expectativas sociales de su gobierno.

El estilo de comunicación que hemos descrito se ajusta perfectamente a lo que Rosanvallon (2009) define como "régimen de presencia". En efecto, el 
autor asegura que "mientras que los compromisos electorales establecen un vínculo que se siente cada vez más débil y altamente hipotético, la presencia [de los candidatos] ofrece su consistencia inmediata y efectiva" (2009, p. 286).

Esta modalidad ha sido reconocida en las visitas de Macri junto al bolsón de residuos al aire libre, en la arteria de tránsito en mal estado, el colectivo de pasajeros y el acceso de una vivienda particular. La Imagen $\mathbf{5}$ también nos ofrece otro caso de presencia del candidato, pero sujeto a la figura de la metonimia. Es decir, esta captura expone el efecto por la causa que lo engendró, de manera que la terminación de las obras públicas (el efecto) remite a la causante que lo originó (el gobierno de Macri).

\section{Conclusiones}

El estudio de las principales imágenes de la mediatización del PRO es una oportunidad para reconocer un tipo de liderazgo que en Argentina adquirió su envergadura a través de la participación de los consultores de comunicación política Jaime Durán Barba y Santiago Nieto (2017a) en el armado de la estrategia electoral de la fuerza conducida por Mauricio Macri. De la misma manera que promueven el estrechamiento de las distancias entre candidatos y electores, señalan la nulidad de las campañas en carácter de instancia de intercambio de programas de gobierno.

Si los espacios de intervención consuetudinarios de las prácticas políticas electorales han mudado hacia las plataformas de comunicación, lo cierto es que el precepto asumido por el líder partidario también ha forjado una práctica renovada de presentación. En la actualidad, indican los autores, no concierne una autoridad que en un período electoral establezca su potestad de liderazgo en razón de una voluntad superior de aptitudes de gobierno, sino a partir de la exposición mediatizada de equivalencias entre representantes y representados, vinculadas incluso a los aspectos más prácticos de la vida en sociedad.

Así es como se establece el actual modelo de comunicación electoral argentino, el cual ilustra la igualdad de usos, intereses y visiones que reúnen a las esferas política y civil. La estructura de los spots de campaña, en calidad de signo indicial, debía, entonces, trasladar al campo de la representación audiovisual una producción "afectada" por los mismos objetos y espacios que transitan los sectores económicamente medios y bajos, tanto de la Ciudad Autónoma de Buenos Aires en 2007 como en la Argentina de los años 2015 y 2019. 
La creación de acontecimientos registrados a través de un dispositivo conducido al servicio de la propaganda electoral ha sido una dimensión constantemente recurrida por la coalición de gobierno. El PRO hizo de este recurso el vector sobre el cual trataron sus principales piezas propagandísticas, con el objetivo de reducir las distancias consustanciales que ilustraron, durante décadas, la relación entre políticos y ciudadanos.

De manera que las subunidades de observación que constituyeron los cuerpos del candidato y los electores, los objetos y los espacios referenciales han conformado una estructura de significación visual de la proximidad que hemos analizado. Creemos que el estudio de las imágenes fijas y en movimiento contribuirá a un reconocimiento más exhaustivo de las campañas electorales contemporáneas. En este sentido, nuestro modelo de análisis puede ser aplicado a las producciones técnicas de otras fuerzas partidarias para reconocer la vigencia en el país de este estilo de comunicación.

Dicho estilo fue adoptado, por caso, en las elecciones de 2019 por la actual alianza de gobierno, denominada Frente de Todos, como, asimismo, durante su primer año de gestión ejecutiva. Así, el histórico Partido Justicialista (su presencia es excluyente en el Frente de Todos) y la alianza Juntos por el Cambio emplean recursos de composición subsidiarios de la legitimidad de proximidad, lo cual permite avizorar que esta cualidad prevalecerá en las elecciones legislativas del presente año 2021.

\section{Referencias}

Annunziata, R. (2013). La figura del "hombre común" en el marco de la legitimidad de proximidad: ¿un nuevo sujeto político? Astrolabio, Nueva Época, (10), 127-155.

Annunziata, R. (2014). Más allá de la promesa electoral. Repensar la representación en Argentina. Revista Sudamérica, (3), 137-153.

Annunziata, R. (2018). "Si viene, yo lo voto": la proximidad en timbreos y visitas de Mauricio Macri durante la campaña electoral y su primer año de gobierno (2015-2016). Austral Comunicación, 7(1), 57-90.

Barthes, R. (1986). El mensaje fotográfico (pp. 11-27). En Lo obvio y lo obtuso. Imágenes, gestos, voces. Editorial Paidós.

Berger, J. (1998). El traje y la fotografía (pp. 43-53). En Mirar. Ediciones de la Flor.

Borrini, A. (2003). Cómo se vende un candidato. Un siglo de campañas políticas en la Argentina. Ediciones La Crujía, Konrad Adenauer-Stiftung.

Bourriaud, N. (2008). Estética relacional. Adriana Hidalgo Editora.

Castells, M. (2009). Comunicación y poder. Alianza Editorial.

Dubois, P. (1986). El acto fotográfico. De la representación a la recepción. Editorial Paidós.

Durán Barba, J. y Nieto, S. (2017a). El arte de ganar. Cómo usar el ataque en campañas electorales exitosas. Editorial Debate. 
Durán Barba, J. y Nieto, S (2017b). La política en el siglo XXI. Arte, mito o ciencia. Editorial Debate.

Groys, B. (2014). La obligación del diseño de sí (pp. 21-35). En Volverse público. Las transformaciones del arte en el ágora contemporánea. Caja Negra Editora.

Gubern, R. (1987). La mirada opulenta. Exploración de la iconosfera contemporánea. Editorial Gustavo Gili.

Iglesias Illa, H. (2016). Cambiamos. Mauricio Macri presidente. Día a día, la campaña por dentro. Editorial Sudamericana.

Landi, O. (1992a). Devórame otra vez. ¿Qué hizo la televisión con la gente? ¿Qué hace la gente con la televisión? Editorial Planeta.

Landi, O. (1992b). Proposiciones sobre la videopolítica (pp. 33-48). En H. Schmucler y M.C. Mata (Coords.), Política y comunicación. ¿Hay un lugar para la política en la cultura mediática? Catálogo.

Metz, C. (1979). El significante imaginario (pp. 9-80). En Psicoanálisis y Cine. El significante imaginario. Editorial Gustavo Gili.

Metz, C. (1991). L'énonciation impersonnelle ou le site du film. Meridiens Klincksieck.

Mitry, J. (1998). Estética y psicología del cine. 2 Las formas. Siglo XXI Editores.

Mitry, J. (2006). Estética y psicología del cine. 1 Las estructuras. Siglo XXI Editores.

Peirce, C.S. (1974). İcono, índice y símbolo (pp. 45-62). En La ciencia de la semiótica. Nueva Visión.

Riorda, M. (2016). Cambiando. El eterno comienzo de la Argentina. Editorial Planeta.

Rosanvallon, P. (2009). La legitimidad democrática. Imparcialidad, reflexividad, proximidad. Manantial Ediciones.

Schaeffer, J.M. (1990). La imagen precaria. Del dispositivo fotográfico. Ediciones Cátedra. Touraine, A. (1998). Comunicación política y crisis de la representatividad (pp. 47-56). En AA.VV., El nuevo espacio público. Editorial Gedisa.

Verón, E. (1999). El verbo y la mierda (pp. 87-88). En Efectos de agenda. Editorial Gedisa. Verón, E. (2001). El living y sus dobles. Arquitecturas de la pantalla chica (pp. 13-40). En El cuerpo de las imágenes. Editorial Norma.

Waisbord, S. (1995). El gran desfile. Campañas electorales y medios de comunicación en la Argentina. Editorial Sudamericana.

\section{Corpus}

Coalición Cívica ARI Malagueño. (2019, agosto 1). Se empiezan...Se terminan. Boleta completa Juntos por el Cambio [Video] [Watch]. Facebook. https://www.facebook.com/ watch / ?V=2522278371167671

Mauricio Macri. (2015a, noviembre 7). En cada rincón estamos juntos [Video]. YouTube. https: //youtu.be/BxzhV3VLb-g

Mauricio Macri. (2015b). Pobreza cero en la Argentina [Video]. YouTubehttps://youtu.be/ AE6b4-K6jTA

Morielli, C. (2011, febrero 1). Las promesas de Mauricio Macri. La Noticia Web. https://www. lanoticiaweb.com.ar/37371/las-promesas-de-mauricio-macri/

Infobae. (2007, marzo 7). Mauricio Macri volvió a saltar el bache. https: / / www.infobae. com/2007/03/07/305245-mauricio-macri-volvio-saltar-el-bache/ 